\title{
What Are the Ethical Problems Raised by the Increase of Cognitive Capabilities in the Defence Structure: The French Legal Structure, the Ethical Position of the French Military Health Service
}

\author{
Marion Trousselard1,2,3, Frédéric Canini1,2 \\ ${ }^{1}$ Institut de Recherche Biomédicales des Armées, Brétigny sur orge, France \\ ${ }^{2}$ Ecole du val de grâce, Paris, France \\ ${ }^{3}$ Chaire Mindfulness, Bien-être au travail et paix économique, Grenoble Ecole de Management, Grenoble, \\ France \\ Email: Marion.trousselard@gmail.com
}

Received 24 September 2013; accepted 24 March 2015; published 26 March 2015

Copyright (C) 2015 by authors and Scientific Research Publishing Inc.

This work is licensed under the Creative Commons Attribution International License (CC BY).

http://creativecommons.org/licenses/by/4.0/

(c) () Open Access

\begin{abstract}
All contemporary discussions concerning the ethics of human experimentation are grounded in the Nuremberg Code (Macklin, 1992) which listed what for many are the basic principles underlying the ethical conduct of human research. By law all scientific researches that use human research volunteers are governed by regulations prescribing the ethical treatment of these volunteers (Jones, 1993). The present purpose concerns what Ethics is in order to discuss about how military researches are directly affected by these regulations. They particularly concern neurosciences and precisely how to improve cognition for military individuals. Main arsenal was discussed according the risk-benefit balance. Furthermore, implications for medical reflexion were proposed. The French law prescribing the ethical principles for conducting research on humans as animals have been successively defined in accordance with European texts (French Public Health Code, 1994, 2004; Favre, Vallet, Renaudeau et al., 2004). All of these have consequences for conducting the French biomedical research for the defence.
\end{abstract}

\section{Keywords}

Ethics, Performances, Psychology, Research, Military Research 


\section{Introduction}

The increase in indorsed and/or on going operations justifies each army to take advantage of current possibilities of increasing cognitive performances for professional soldiers. Within NATO each nation has defined, statutorily or not, the work terms and conditions of some of the available means depending on operational restrictions. If the international context of missions requires a consensual pragmatic position for the forces' operations in the field, the definition of a shared employment can only economise on ethical thoughts surrounding the question of increasing cognitive performances for professional soldiers. This raises the question of why do it, to what limits and with what means? If these questions fall within the jurisdiction of military ethics, they inevitably involve biomedical research from each country's defence. This type of research has dual characteristics, engineering and medicine, which gives the combatant a dual status, that of a citizen and also a component of a weapon's system. This double outlook highlights ethical questions arising against the current potential of increasing cognitive capacities in human beings. A distinctive French feature lies in defence biomedical research led essentially by doctors, which subsequently places all analyses conducted under the watchful eye of medical ethics.

\subsection{Positioning Ethical Thinking}

\subsubsection{What Are Ethics?}

Ethics are defined as a system of principles governing morality and acceptable conduct (Briole, 1996). If we consider ethical semantics we discover two witnesses of the ambiguity of these ethical sources. For the Greeks "ethos" is the distinctive spirit of a culture or an era. This last idea was adopted by the Latin in "Habitus" which gave the French "l' habitude" and in medical jargon "l' habitus", in other words, what we resemble by the iterative way of our behaviour. In other terms, ethics are only a science which appreciates the way in which we behave. This definition has a meaning in Greek philosophy in which the individual owes it to his/herself to get to know oneself and to fully aexpress one's reason for being. A full life is a life that fulfils birth's promises. Existence illuminates the essence of being. This definition holds no notion of morals. It is the emergence of Christianity that will bring notions of "good" and "evil" and the vectorization of the behaviour which is evoked from the notion of paradise and hell. So it is imperative to separate all ethical judgement from moral judgement, even if conditioning pulls us in this direction.

Ethics, by definition are individualized, have nevertheless been compartmentalized. Observation shows that even if each man is unique, he nevertheless shares a certain number of characteristics with his fellow beings, and has ethical foundations. In other words, taking into account the normal behaviour of the human species this is the minimum to which I must conform, effortlessly as it is simply the expression of my humanity. Yet, on reflection, human ethics are a patchwork based on "a fundamental animal ethical layer", and a societal and cultural layer. The ethics that we speak about are the behaviour of a primate human modelled in our occidental civilisation. Within this logic, ethics are defined according to laws laid down in our occidental society. The collection of references (conventions, declarations, charts, philosophical thoughts, etc.) only reinforce the occidental point of view of the normal behaviour of man, in other words, that which he cannot breach without risking leaving the status of man. Likewise the normal behaviour of a serviceman is governed by the Geneva and La Haye conventions. The definition of this normal behaviour has another repercussion to guarantee harmonious living conditions within society. Likewise, individual ethics of a French citizen nestles in the more complicated togetherness defined by the civil code which governs interactions between men and the penal code imposing sanctions pertaining to isolated cases in life within society. It is here that we can consider ethics as "positioning itself one degree higher than morals. It is what is required from everyone outside of the sense of obligation" (Briole, 1996).

\subsubsection{What Are Ethics to a Doctor?}

If we accept the primary definition of ethics, doctor's ethics are simply everyone's normal expectations of someone yet carrying the status of doctor. Here there are no morals: a doctor must simply carry out what he has promised at the time of his thesis in the Hippocrate oath. This behaviour will in time become a habit, then a habitus. The individual chose to become a doctor and found himself transformed into a doctor. This founder text that describes the behaviour of a doctor was broadened by other texts which defined how occidental doctors are seen in society: the ethical code. It encompasses a collection of rules governing an occupation with professional sanctions that pertain to it. 
This rather abstract definition of a doctor's ethics is made operational by observation and thoughts on the practitioner's facts and acts reaching a case law which concludes by modelling a doctor's expected behaviour in that given society. The dynamics of the ethical code imposed by the evolution of society and science, suggests a safeguard for doctors to help them behave in accordance with their status in delicate situations in which they could not have a spontaneous point of view.

This thought process would be simple if relationships between patients and doctors were only governed by the ethics of the citizens and the doctors. With the eruption of the stakes in biology, society has found it necessary to define the conduct of a professional individual working in biology, contributing to the arrival, in the seventies in the United States of America, of a new science, bio-ethnics. It was a turning point that ascertained that the power of life had escaped, at least partly, to the doctors and it had become necessary to think of the power of man outside of medicine. According to the German Hans Jonas "bioethics allows us to think, and by freely allowed obstacles, to prevent man's power becoming a curse to himself” (Jonas, 1990).

\subsubsection{What Are the Imposed Limitations for Each Biology Protagonist?}

For doctors, limitations are clearly defined by the Hippocrates oath, which as a last resort sets the medical conduct "primum non nocere". This injunction is equivalent to the Hippocratic vision, very paternalistic, which places the doctor as sole judge of the legitimacy of this therapy. This antiphony shows the limitations that the doctor imposes on his work to obtain the best results for his patient.

This relationship has evolved in time and today relations between doctor and patient are made on a one to one basis, the doctor's knowledge encounters the patient's courage. The two protagonists, in their own ways, founder the dignity of their existence. Dignity is something that belongs to the individual, that comes from his acts and he must place himself at the height at which he believes in himself ("decet", that which is suitable) in order that the other awards him aristocratic "dignitas". If the notion of dignity adjusts itself to the centuries, it has always represented the conduct of an autonomous being marked by God (Christianity), by education (renaissance), or by reason (age of enlightenment). Dignity therefore appears as the consequence of an ethic put into practice in a conduct that honours the one who does it. It is without doubt within the same ethos that this enlightened consent founded the medical act. This approval is based on the honesty of the doctor's explanations and on the patient's awareness once a therapeutic agreement has been decided.

This behaviourist approach of ethics comes up against the Kantienne definition which takes pride of place (8). Kant places dignity clearly within us, which in other ways provides a limitation that is not only down to us to respect, but which must also be respected by others (or by delegation from the state), and which can be called upon to thwart freedom. Currently in France some lawful decisions approve an idea of dignity as a superior value for the freedom of man, which signifies that the individual does not belong to himself, and does not define himself in relation to himself but in relation to his adherence to the human genre, reduced to its genome. The text depicting the first French bioethic laws says "the law ensures the person's primacy, prohibits any restriction to dignity and guarantees respect of the human being from birth" (Jones, 1993; French Public Health Code, 1994, 2004). If the fact of living has a clear biological basis, the genome, the text by adding the protection of a human being's dignity involves that of the human species implies a prohibition of transmitting a genetically modified patrimony to later generations. The European texts also delineate this importance of respecting the human being as an individual and as a member of the human race. The Kantienne logic places a limitation on the essence of man more than on the individual (Kant, 1788).

To summarize, the limitations which impose themselves on each biological protagonist rest on the last analyses, on the idea of no-one, that this must be included as an expression of essence, or the incarnation of dignity by ethical conduct. To define the person is a question of major bioethics depending on the limits of one third of one's actions, notably in research, but still the capacity to access oneself in all that includes the body and cognitive functions. Etymologically the word hailing from the Latin term "persona" reflects the actor's voice from behind a mask.

In fact, this was what society perceived from an individual, up to the point of attaching a name and particular rights to the person, instituting the individual of the law. This definition leaves a fundamental ambiguity to the individual, which cannot be divided, even if society sees a social mask and himself in character, a real person. Enlightenment has connected to this person, sacriliged by Christianity, an autonomy founded on reason and enduring rights. This procedure set out in the current bioethical laws marks down the respect of fundamental rights within the heart of the subject. 


\subsubsection{Summary}

It is indispensable to resume the key ethical points before seeing how the emergence of neuroscience is a genuine challenge for ethical thought. In the biological field, the limitations on human activity are taken from a transcendental viewpoint by the human community and from a behavioural perspective the need of the various protagonists to behave according to their social status, that is, following the country's specific laws and professional ethical code. Also from an emotional perspective, it is important to recognize the otherness of the patient. This recognition is necessary for a loyal therapeutic relationship.. The pre-requisite of these viewpoints is the complete autonomy of the subject who will only allow what he wishes to show to another.

\subsection{The Neuroscience Revolution}

\subsubsection{The Scientific Explosion}

There is a current revolution in neurosciences which answers to the psychopharmacology which started in the 1950's-1970. Visualising the brain working live by MRI enabled an understanding of the mechanisms that underlie behaviour. These scientific skills of decoding someone's behaviour breached the considerable gap in the individual's autonomy. Great is the temptation to use this means of investigation to use the power in terms of truth (judiciary domain, lying detectors), of economy (development of neuromarketing), education (development of teaching methods) and defence. Great also is the temptation to optimize the individual's capacity to make them suitable for missions requiring ultra performances.

In defence, the temptation is to put everything at one's advantage to ensure his mission in what can sometimes be in very difficult conditions. If the behaviour of a combatant facing his alter ego from another army is well defined, if it is not respected, the behaviour of combatants facing themselves remains difficult to distinguish. This is where the problems of ethics arise. In this discussion there are three protagonists: the commandment in a wider sense who organises the missions, the autonomous combatant whose level of involvement is fixed and the doctor who takes care of the combatant's health. There is also a local framework, individual and communal, a general framework, legal and professional and an international framework.

With the emergence of neuroscience, the optimization of human capabilities arrives at the problem of doping, but does not resolve itself there. It exceeds the mechanisms of the traditional pharmacological approach by the mechanisms of the neurophysiological, which gather up more conditioning. Taking drugs does not only operate the neurone network beyond its capability by the addition of drugs, it also profiles the individual's brain on an antiphony detrimental to its multimodal ability to decipher the world. The potential cost to pharmacology is the physiological health and its restriction of mental conditioning.

\subsubsection{The Cognition Case}

Cognition can be defined as a collective process put into practice by an organism for treating information that he meets. This includes necessary elementary skills for acquiring information (perception), for selection (attention), for consideration (representation), for remembering (memory), for confronting what is expected of oneself (detection and error), by others (social confrontation), for linking it to an anticipated reward/punishment (reward), for reacting by consequence, that is managing our behaviour, by resolving problems and taking decisions (executive functions). Ultimately, what guides behaviour is a togetherness linking a more or less honed perception and directed from the world, the subject's history in terms of conditioning, the level of coherence between what the subject expects to do and what it must do in view of the world.

How do we define the rise in human performance in the field of cognition? Technically it is relatively easy to do a qualitative, quantitative and subjective appreciation of the level of the cognitive performance of a subject with a reasonable level of reproducibility. To realise a simple cognitive task, the performance is assessed by the "error rate". For complex tasks, the cognitive capability is indirectly apprehended by measuring the error rate by carrying out the specific simple tasks on paradigms modelling the complex task. It is also often calculated by the assessment of several cognitive functions that we think they construct their polyfactorial dimensions (supported and shared attention, distraction, auto-calculation, judgement, executive functions, etc.). The idea of cognitive capabilities implies therefore the definition of standards, starting from the distribution of measured cognitive capabilities in a population with identical socio-demographic characteristics. This classic definition of performance unfortunately does not take reality into account. Looking from a society's perspective, the military represents a population which is trained in its line of work, with optimized capabilities for undertaking a specific task 
(marksman/woman, echo listener-“oreille d’or”) or not (aerobic or anaerobic capability). Therefore it can only be assimilated to an average population. There are no other standards possible other than those of the evolution of the performance of a given individual and more precisely, those in a position that look after this evolution in a population of evolutions concerning subjects who are submitted to identical training. It is necessary to point out that this definition of performance has a sense in the military only in terms of performances obtained in situations of stress. That means non-deterioration of performances. One must therefore ask what the objective is: would the aim of the training be to develop exceptional performances in a situation of psychic calm but extreme fragility in a situation of duress, or to develop a resistance for the individual to a restriction which ends by protecting the few standard performances of which he is disposed (idea of hardening)?

From a neurophysiological viewpoint, a performance is a specific behavioural entity of which expression requires a limited number of neurophysiological mechanisms. These mechanisms can be optimized by specific exercises but also by playing on the non-specific mechanisms. This optimization is held in other performance fields. The increase in cognitive performances can be defined as an extension of one or several of these generic capacities of treating information whether by internal or external action on the required process in these skills.

\section{Available Arsenal}

The arsenal currently used for increasing cognitive potential of the individual is vast. The plan of division between what is and what is not legitimate is the whole stakes of ethics in this field. To begin with we are studying the existing models by simultaneously raising ethical problems that this unearths before thinking about the division plan.

\subsection{Education, Enriched Environment and State of Health}

Education is a strategy for modelling an individual so that he can participate better in the social activity of his group. This leans on the fundamental multi-modal conditioning linking apprenticeship motors, mnestics, logic, artistic and social. Therefore, a child who grows up in an area of enriched development and lacking biological and psychological stress optimizes his cognitive capabilities by the plasticity of his cerebral network and develops his capability to resist duress. This optimization that installs itself in prenatal, perinatal or post-natal periods has the advantage of being perennial (Roubertoux, 2004).

This basic education is a pre-requirement so that armies dispose soldiers that have the emotional stability facing duress enables the development, under the restriction of events, of a thought process as serene as possible allowing each to carry clear judgement or at least the best possible, of acts to undertake. Developing individual citizens to be fully responsible for their actions is therefore the first means of improving cognitive performances under duress.

\subsection{Mental Training}

Mental training is a vast collection of grouping techniques aimed at acquiring specific aptitudes. It contradicts education in this character focused on knowledge. For the most part, this training concerns non declared memories ranked where it is needed to organise the skills (detection capability of "echo-listeners", or assembly/dismantling of jammed weapons). This training develops aptitudes that are non-degraded by combat stress and safeguards the combatant's operational capabilities.

Also, mental training can be directed towards controlling emotional states. A great number of techniques (yoga, relaxation, mental visualisation of performance, etc.) are classically used by elite sportsmen/women or in functional re-education. It leans on the capability of controlling the cerebral activation level by mastering the informational flux stemming from the body and primarily from ventilation control. This training for mental control only improves performances by playing on the importance of deterioration linked to stress. Contrarily to specific training this type of exercise reflects on the quality of life of the subjects who take part. For all that, their efficiency when faced with more complex life situations still remains controversial.

\subsection{Nutritional Supplements}

Cognitive performance is obviously dependent on energy metabolism and of energy availability as far as the 
brain is concerned. Certain food supplements have been identified as having consequences on the brain's structure. This is for example the case when supplements are used during pregnancy with polyunsaturated fats (w3 and w6): contributions seem to take advantage of the development of cognitive capabilities of a child by acting on the membrane plasticity and encouraging formation of synaptic connections (Helland, Smith et al., 2003). These supplements are also used in the event of neurological accidents to improve functional recuperation. Among healthy adults nutrition intervenes on cognitive performance in a wider sense. Tea and polyphenols could reduce anxiety, coffee slows up the on set of Alzheimer's, etc. We have evoked effects of certain amino acids found in proteins on the modulation of the synthesis of neuromediators (tyrosine and cerebral catecholamins, amino acids and serotonin, etc.) This nutritional approach can be taken advantage of by coupling it with genetics in order to define the ideal supplements according to the genome of each individual. All that remains is to begin compensating but many deliberate functional modulations by orientation of the metabolism which it postulates.

In this framework it is not about maximizing the performance but rather in reducing the deleterious effects than exposing it to a generic act of aggression and therefore contributing to keeping the individual's good health. This analysis must be considered by the fact that these substances, taken during the time of exposition to stress, contribute to lengthening the time of the presence of the combatant facing his aggressors. Therefore it increases the length of performance in conditions of duress and so in its use plays a role equalled to doping. The individual, due to his use of these counter measures, more intensively exploits his brain and runs the risk, theoretically as it has never been calculated, of more serious pathological stress (burnout, heightened states of stress, alexithymia, etc.) So is this really the right moment to use a substance, is it as innocent a pharmacological viewpoint as a nutritional substance, which generates the feeling of doping and is not only the substance.

Outside this official report, it is within a very unusual context that it is necessary to think of using counter measures against deterioration of performance. What is brought into the idea of doping does not reside in the substance used but in the intentions of the act. If the aim is therapeutic, so the exclusion of the constraint indicates that the use is therapeutic. In the opposite case, the deliberate attitude under the constraint indicates the intention of doping and puts the subject at risk of injunction both of the constraint and of the substance.

\subsection{Conventional Pharmacopoeia}

The use of mind-altering substances to benefit from cognitive skills or to face a frightening situation is imposed since the customs of ancient times. Arsenal goes from anxiolytic relaxing agents (hydromel; the nectar of the gods, alcohol, marijuana), to activator agents carrying a stimulant (caffeine, tobacco, coca), to agents generating an automatic relaxant (chewing gums). If these generic products carry a better sensation of wellbeing in conditions of war, it is difficult to speak about the optimization of performance. Discussing stimulants, it is about keeping a certain level of performance at a time of circadian rhythm when they are particularly deteriorated (1 am - $3 \mathrm{am}$ ). Concerning the anxiolytics, what is needed is to reduce emotional activation to a level that allows a minimum of cognitive thought.

The pharmacological deal has changed radically with the use of stimulants such as amphetamines and Modafinil. These substances were developed by the pharmaceutical industry with therapeutic purposes in mind. Modafinil is situated in the hypersomnia idiopathics and Gelineau illnesses benefiting those who have authorization on the French market with limited prescriptions from specialists. Independently to any ethical considerations and efficiency criteria, the use of these substances in a military context presents two theoretical difficulties. These substances were evaluated in a pathological context for their therapeutic efficiency and in a physiological context for their harmlessness in normal use, i.e.: in every day usage. Their use in a context of stress poses the problem of the pharmacology of a brain under stress. Besides the fact that stress deeply modifies pharmacokinetic characteristics and pharmacodynamic basales, it modifies the function of the brain independently to the action of the substances. This can produce potential effects that topple over a controlled dose from harmlessness into risk. These effects create genuine medical problems, regardless of the use or not using these drugs. It is necessary to know their pharmacological characteristics under stress so that whoever takes them in a state of stress does not risk any mistaken side affects. Here there is a whole spectrum of pharmacology of phase IV adapted to military conditions. The second neurophysiological problem that raises the use of these substances in situations of stress lies in their neurobiological specificity and their selective impact on certain functions. Like this, the tract dopaminergics are reputed to intervene largely in the evaluation of risk and reward. Modifying 
their function by these substances directly impacts safety, particularly in the event of decision taking under intense psychological duress. Therefore it is essential to know the impact of these substances on the elementary cerebral function in a stressful situation. The third problem concerns the variability between several individuals. The same dose of a substance does not necessarily have the same effects from one individual to another. This variability must be accounted for in evaluating individual risk.

Emergence of a notion of risk linked to concomitant display to the constraint and the stimulant raises the problem of benefit outweighing risk factor. Keeping an individual stimulated carries obvious benefits in a survival situation, but questionable when this is not the case.

\subsection{Genetic Modifications}

Since performance runs directly from the brain's function, it is obvious that any modulation of the genome can have an impact on certain performances. Yet there is no direct and linear relation between the importance of genetic modification and the importance of its impact on behaviour (Roubertoux, 2004). Among animals relationships are shown between expression modes of the glutamatergic receptors NMDA and the mnesic capability, but studies conducted among men on the same genetic targets calculate their role in the modifications on the capabilities to mnesics at 5\% (de Quervain \& Papassotiropoulos, 2006; Craig \& Plomin, 2006).

Another alternative concerns research of the alleles of certain genes crucial to behaviour (glucocorticoides MR receptors, recapture site for serotonin, etc.) susceptible of being a modification carrier affecting a small number of nucleotides but deeply modifying the function of the resulting protein. This modification can play in a positive sense, or can be deleterious. There exists a temptation of selecting individuals who are more apt at a particular function. A medical point of view can in no way caution this selection. The use of this knowledge can only be therapeutic (an individual carrying such a polymorphism and presenting a pathology could need a heavier treatment) or possibly preventative to a recurrence (the presence of this polymorphism increases the chances of risk of recurrence).

\subsection{Computer Technology}

Methods leading to improved performance can involve the use of erogenic assistance (Engelbart, 1962). Research carried out on man-machine interfaces is the heart of the problem. The role of external computer systems is considered as progress without implying the need of man and in fact asks few ethical questions. Training on a simulator is a laden example of this. It is not only about learning one's job, use of a simulator can also produce a certain number of psychophysiological disagreements.

In the same way, the use of software is encouraged to free the individual of routine tasks. This strategy directs the placement of help systems (expert systems) or information research when the given number is too great. At this level a genuine entanglement exists between individual and machine and the man-machine interface is no longer an instrument panel but a logical action. The first step is training the user to adopt machine logic. The ultimate step is to intimately integrate the electrode bias command implanted in the brain. We talk about the development of an "exoself" that we barely master the effects in terms of self-perception and our relation to the world (Mann, 2001; Mann \& Niedzviecki, 2001). This move can seem like science fiction but is part of an active development in the area of large handicaps.

This technological evolution raises the problem of man's status in the centre of the machine. Man is monitored by intelligent sensors which determine the level of vital risk (monitoring the wounded, tolerance to a hot environment, etc.). Conversely the machine can delude man's perceptive systems in such a way that the pilot acts correctly. In this way he is recognised as legitimate by wanting to boost the spatial orientation capability of pilots by using a jacket fitted with intelligent proprioceptive sensors, which indicate the pilot's position in a terrestrial frame of reference. As Bernstein facing G. Gould said, "who is the boss?” What is man's status when placed under the surveillance of his machine and what is he free to make a mistake or to be unpredictable in algorithm terms. Is it this unlikely start up that makes the pilot less vulnerable if facing a logical algorithmic analogue?

\subsection{Collective Intelligence}

Improving cognitive capabilities can not only concern the individual, but also the group that he is a part of. An 
individual's competences are shared in a group to increase the group's cognitive performance. A certain number of tools and procedures are developed to improve the intellectual collaboration between individuals by focusing on communication systems and representations within the group formed. Currently, research is riding on the development of connective intelligence by taking advantage of the dynamics of information communication (Warwick, Gasson et al., 2003; Surowiecki, 2004). The open system Linux is a well-known example. The developers of Twitter followed this objective by advocating the development of this experimental platform on the social network.

Privileging collective intelligence to heighten the potential of a group does not come without raising ethical questions. Everything resides in the balance between specialisation and versatility. An excessive specialisation reduces the individual to a tool for the group's service and the fact to work independently to the group effect. This tailoring strategy has possible repercussions on mental health and subsequently on physical health. Human society assumes that individuals work in intelligence (inter-ligare), that is, that they use their knowledge and know-how for a common aim and they react to the consequences of their actions.

\subsection{Nanotechnolgies and Nanomedicine}

Nanomedicine equates to "a domain consecrated to health, which uses knowledge acquired in medicine, biology and nanotechnology. Most often to produce, on the scale of molecules and cells, nanometric tools, with the view to diagnosing or treating illnesses, to administer medicines and repair, reconstruct or replace tissues or organs” (nanoquebec.ca, 2005). It opens up a myriad of possibilities of encapsulating cells, which under electromagnetic stimulation, could free neurotransmitters ensuring in this way an increase of cognitive capabilities. The potential wellbeing is fascinating, yet the risks often unknown. The stakes are both complex and major, ethically, legally, socially and politically.

In 2006 the International Institute of Research in Biomedical Ethics held the sixth international seminar and supported nanotechnology and especially nanomedicine. The nanosciences are not a product of a scientific revolution, but simply the inevitable result of technology development. The fact that release of transmitters is from nanotechnology or genetic therapy or from systematically taking a medicine does not change anything from the foundations of logic, but it improves the technological specificity of the cure. Despite this and notwithstanding a still distant applicability, the stakes hypothesised by nanomedicine are perceived as being at the edge of founding numerous calls for reflection expressed for the last twelve or so years by a vast amount of experts from all circles. At least two competing reasons explain the urgency. The prefix "nano" is susceptible to such varying senses, it invites an imaginary, the rate of developing technology risks cutting short former sociological reflection indispensable to ethical standing.

This question goes back to the source of ethical thought. There is a confrontation between technological development stimulated by medicine, ethical thoughts returning to the way in which a society thinks of itself and small groups susceptible of using technological development in the context of their activity. The ethical stakes are to agree to these ideas by positioning everyone culturally and in the society to which they belong. The use of technological developments in defence stretch the limitations on ethics which have as many limitations in efficiency, but which represent limits that a society give to its means of defence depending on the level of the act of aggression which is faced. Military ethics exist just the same as medical ethics do. The two are not confused and are used together to mark out the defence's action limits. Military ethics authorize the military in the context of their actions and they conform to the national and international laws. Medical ethics in the defence are what they authorize in relation to themselves so as not to injure anyone serving within this context.

\section{What Are the Consequences of Increasing Cognitive Capabilities?}

\subsection{The Relationship with Medicine}

Progress in neuroscience enables improvement of a human's capabilities. This possibility is of interest to a society and an individual's desire to outperform his limits, a desire already outlined in the bible ("eritis sicut dii"; “you shall be like gods” according to the devil’s promise, Genesis). It is about excelling (or at least improving) a man's capability and not restoring a damaged capability due to a sickness or handicap. The principle divide of reasoning in medical ethics resides in the aim Medical versus Operative, which is not the case for military ethics. The border between the therapeutic act and action in view of improving cognitive capabilities is not waterproof. 
Plastic surgery or contraception, mainly developed in medical practice even though they do not have a curative or preventative action, shows that our society accepts that we can modify our bodies to live life better. The same goes for the psyche as we are witness to the development of psychotherapies, psychological management techniques and diets. The frontier is not in the act itself but in its intentions (treatment, to feeling better), from the beginnings of the individual who is lead there (the action is applied to oneself) and within imposed limits. The latter thinks in terms of benefit/risk factors. Again is it necessary to determine what is the risk often reduced by inapplicable statistics to a particular individual, and what are the benefits? This evaluation places itself within a society and its culture at a given moment in its evolution. The standard ethics, with the same status as the law, cannot be removed from social fact. In this context, calculation of the benefit/risk factor is the fact of an autonomous individual, duly informed by a professional of the objective risks (albeit statistics) that he incurs and has a clear conscience of his desire and motivations that he expects. We immediately perceive that the limits of this approach coagulate in the idea of autonomy. Autonomy understands itself in relation to oneself (to be capable of understanding and reacting in a level headed manner) and in relation to others (to be free to react according to one's own feelings and not to a trend or pressure from a group).

In the context of the defence, the relationship with medicine is more complex. What can be allowed in an individual case cannot necessarily be allowed in an institution. Independently from a society acceptability benefits of boosting the potential of capabilities, which appear more collective than individual, oblige an intransigence on the level of risk. This boundary is as essential as the modifications made in the name of collective integration (to undertake for becoming apart of this, or that defence group) can impact personal lives which are modified by the nervous system of an individual and not a behaviour in a given area of his life. There is no temporal limits, neither a predefined sense of action which is worth a definitive ukase. A short-term benefit can become a risk in the long term such as an addiction to certain substances like amphetamines. On the other hand a risk in the short-term can become beneficial in the long term, such as stimulants in a situation of peril. Outside of these conditions of use, there exists a boundary of natural medical taking into account the repercussions on health due to growth methods of cognitive capabilities. The substances used, disregarding the methods employed (authorized or illicit), must be done with maximum safety. This requires an active scientific surveillance in the area to have knowledge of the potential side effects which may occur during use in a stressful situation.

\subsection{Consequences Concerning the Autonomy of the Individual}

This question does not reduce the medical risk following the use of medical products but also the risk of affecting the private lives as soon as we adopt computer technology, of collective intelligence. Protecting the information collected from research in neuroscience, in particular in neuroimagery and neuroinformatic, holds very sensitive stakes. In fact, the collection, treatment, conservation and potential uses raises many questions in terms of consent, confidentiality, non-discrimination, information rights and advice. For example, recruitment agencies or insurance companies could search to obtain information at the end of their selections. Therefore it is necessary to protect these personal data and the scientific interest of exploiting such information.

Neuroscience development gives tools to analyse particularly competitive behaviour, which presents a problem to an individual's autonomy in the decisions he has to take. It is possible to separate subjects who are sensitive to the environment to subjects less sensitive to the environment in the context of research on the placebo effect. These methods separate the modalities of varying cerebral functions and therefore different vulnerabilities.

On the basis of this knowledge it is possible to manipulate the individual so that he reacts as he would in a group. This risk is linked to all groups of individuals and depends on the level of knowledge of psychology of those intervening. Knowledge of indoctrination methods and neurobiological mechanisms to carry out increase the efficiency of this indoctrination and shows the intentions of the conduct, assigning the individual to a task that he will not reap the benefits. Blindly playing in medicine with the placebo effect is not the same thing as playing with the placebo effect knowing the classification of the individual. Once again the difference is not in the act or the objective, but in the level of knowledge, with the performance and the intention of efficiency that this implies.

In particular, the level of indoctrination and education intervenes on the behavioural balance between egotism and devotion to the group. If a strictly egotistical strategy is harmful to society (20), an excessive indoctrination is clearly harmful to the individual. This balance is not only modulated by psychotropic substances (Booth, 2005; Kolnai, 1976; Naboun-Grappe, 2000), but also by mental conditioning (look at the problem of sects and more 
generally that of coaching). Therefore it is possible to make a simple separation between chemical and psychological methods. Therefore it is studying the effect on autonomy where it is necessary to research the validity of such strategies: toughening up is not necessarily indoctrination.

\subsection{Consequences in Terms of the Identity of the Individual}

The identity of the individual is an emerging ownership of the cerebral function and it appears plausible that any modification of cerebral function by psychological or physico-chemical methods have repercussions on the subject's identity. In particular, very clear links have been described between personality and neurobiological status, that it concerns the function of neuromediation or the activation balance of different cerebral zones when facing a given constraint (Cloninger, 2000).

The individual's identity does not restrict his personality, but also his social status. The first step to social respect is obviously the respect of one's body, including the nervous system. It is out of the question, even with all the good reasons in the world, to transform man into an actor without his autonomy. The social game on autonomy implies inert-relations ensuring psychic shoring at the cost of emotional subjection. In this context, the freedom of an individual facing psychic growth strategies is minimal. It is equally in the context of this social group where the process of reward (punishment) is set up reducing the identity of the subject to his position in the group on the basis of a mastered activity (bomb disposal) or a social role (scapegoat). It is in this position that the question is raised of freedom of choice of the individual making use of external assistance for his cognitive, but also emotional, function. For such an individual to implement cognitive capability expansion techniques has little chance of leading to a modulation of free will...

Restriction of these systematic cognitive capabilities as a price to pay of scientific training has consequences on the perception of identity. Is it easy to separate technical training from identity focusing around mastered capability? Such a separation requires that a counter culture be applied at the same time, developing other non-professional capabilities to which the identity could be attached.

\subsection{Consequences in Terms of Authenticity of Cognition: The Question of Nature versus Nurture?}

The expansion of cognitive capabilities of an individual raises the question of what really belongs to him. Does a difference exist between natural talent duly trained and a nurtured performance. The latter is often linked to an action coupled with cerebral malleability resting on a pharmacological and nutritional viewpoint and a functional training viewpoint. The question is no doubt the same for a sportsman developing his muscles for physical resistance indispensable for practicing his sport. There is a freedom of action more advanced than functional growth which separates behavioural function from talent. The table is relatively similar for cognitive training: to develop one's memorization capabilities, one's skills and cognitive short cuts (mental calculation, knowledge of procedures), not acquiring inventive behaviour when facing a constraint. Development of cognitive capabilities only has an impact on the talent of an individual when he also uses superior cognitive functions without reproducing any mental schema. It is in creativity that cognitive authenticity nestles, the rest is simply knowledge guaranteeing minimal performance in a situation of duress.

\section{The Legal Framework of French Bioethics}

\subsection{Introduction}

It was after the 1980's, ten years after the USA that France began reflecting on bioethics, by demanding the inclusion of these principles in the rights. In France, three laws of bioethics were adopted in 1994 and revised in 2004 in the form of one sole law, with a worry of finding "a point of balance between protection of fundamental rights of the person and non-hindrance of progress of research" (Applications of French Bioethical law, 2008). 2009 should have seen the release of a revised project of this French bioethics law (Estates General of Bioethics, 2009). From this perspective, the Biomedicine Agency and Parliamentary Office of scientific and technological choice were in charge of filing an application report concerning the 2004 law of bioethics, and the national consulting committee of ethics of "identifying the philosophical problems and ethical interrogations that arouse this meeting". What's more, these three institutions were interrogated on the pertinence of spreading out the field of application of the law to new disciplines, and notably to neurosciences, which for the moment were not ac- 
knowledged in the texts.

In fact, the neuroscience project cannot be summed up as "brain science", it entails studies of behaviour, interactions, mental life. This area of research engenders fears and fantasies, exacerbated by the media coverage from which it benefits. The last few years have seen the emergence of the "neuroethic" concept, that L. Kass, prior director of the American President Advisory for bioethics, defined as the discipline which "embraces the ethical implications of neuroscience and neuropsychiatry advancements", including as well as the technical aspects (use of psychotropes in cerebral stimulation), as the consequences (Kass, 2002).

\subsection{French Perspectives}

Several legislative dispositions appear necessary to answer to the ethical stakes brought to light by neurosciences. In this way, the future bioethical law could take the form of a strict law, defining the major ethical princeples on each theme, rather than that of a detailed law, which, sooner or later, will turn out be incorrect. This system will be more advantageous by being more flexible and reactive: the law could be revised as soon as it appears non-adapted to a situation, on suggestion of one of the French bioethical organisms. Looking at it from this perspective it would be wiser to redefine the areas of expertise of the different independent agencies. For example the agency for biomedicine could play a regulating role in interpreting the law depending on the practical applications encountered. When a specific case would appear to be a substantial contradiction to the law, the agency could "hand-over" to the legislators who would decide how pertinent the modifications are. That leaves the fundamental ethical principles to be defined by this law, of which a certain number could be transverse to the disciplines of biology: the principle of primacy of a person's dignity, of the inviolability and the non-commerciality of the human body, of freedom of consent and fair minded access to care.

Some underline the relativity of progress brought about by neuroscience to current times in comparison to provoked hopes or fears. Ethical debates weighed on the possible technical repercussions still under development, would only in their view, contribute to trivialization of the fantasies. It would be more sensible to interrogate on the evolution spawned by neuroscience in terms of representations like the "cerebral subject" of the human being in its relationship to the world. In a mechanistic vision of the mind, come what may, of complex ideas from sciences, human, lawful and social (responsibility, socialisation, freedom, etc.)?

\subsection{Where Can Neuroscience Be Situated in Bioethics Laws Elsewhere?}

Neuroethics enable the debate to go into greater depth and therefore clarify polemic exchanges. The AngloSaxon countries in particular are very advanced in this area of research and the last few years have seen neuroethical programs multiply in prestigious universities, principally American and Canadian. Alongside this the media gets hold of the subject and relays interrogations lifted from the seminars reuniting specialists from all over the world, such as those from the neuroethics international network. The Anglo-Saxon approach is therefore based on educating the public and talks, most notably thanks to the initiatives of the National Institutes of Health (HIH) and the Society fro Neuroscience (SfN). In 2004 the American president's counsel for bioethics held several meetings concerning neuroethics to raise questions on various problems but without ever expressing recommendations. In Great Britain, the Nuffield Council on Bioethics, a private organization that deals with bioethical questions for the government, since 2006 has published a report in which it identifies in an exhaustive way the various questions linked to advances in neuroscience. However, whilst examining the British laws on bioethics in May 2008, the House of Commons did not explicitly include neuroscience. The remarks on neuroethics brought to this country have therefore not reached legal dispositions.

\subsection{Summary}

Progressives in neuroscience call to open the ethical debate by getting together the greatest number of persons. Within this perspective in spring 2005 the Meeting of Minds was organized which gathered citizens of nine European countries, including a French panel, in order to question them on the implications linked to discoveries about the brain. This initiative created a presentation from thirty seven recommendations possible in front of European politicians, which demonstrates at what point the public's commitment on such questions can be productive when endowed with a developed sense of scientific reality. The general state of bioethics which starts in March until June 2009 in France represents an opportunity in this area. 
Finally, more widely, it must be acknowledged to imagine the inclusion in school programs of education in bioethics and even teaching which favours a better understanding of science and technology, the foundations of progress of a democratic technique. This “science educating citizen” would be able segregate what comes under the probable from what comes under fantasy and avoid mixing up science and science fiction in the discussion.

In the end, neuroscience has strong potential for implementation and therefore must be supported by the authorities. Currently arousing ethical debates must not lead to a decline in research in the material but an accurate framework to draw out the best results. A blue print law defines the major ethical principles of scientific research enabling answers to numerous ethical questions already created by diverse disciplines in biology and revived by neuroscience. What is more, concerning specific questions, such as for the protection of personal information issued from neuroimagery, specific legislative dispositions could prove necessary. Unrealistic or purely speculative declarations come in addition to fuel the mistrust in society and the outcome diverts its attention from the genuine stakes: an effort in communication and teaching needs to be tackled, in particular by the scientific community.

\section{Where Does the French Health Service Position Itself?}

The Health Service manages the defence medical research and serves the forces with the lawful mission to warn, protect and treat the troops. It is completely immersed in the legal framework of bioethics and therefore in work concerning the best possible plans of prevention, protection and care of combatants in their environment of preparation and battle. But it is also hierarchically subjected to the demands of the commandment, which can impact the development of tools and systems enabling the improvement of a combatant's performance which in no way intervenes with the health service's mission.

This dual subordination of bioethical research of the defence is a French peculiarity, because in defence research most occidental countries have dedicated the missions of developing tools and systems for increasing performances in specialized establishments composed of engineers and researchers but not doctors. And yet, it is important to remember that doctors are before everything governed by the deontology medical code, in particular article 5 which states that medicine cannot alienate its independence under any form not matter what (Decree $n^{\circ} 79-506$ of the Military Medical Practices), and only its ethical outlook in comparison to its scientific activity retrieves from a grown vigilance in the military institution.

In this context the responsibility of the researchers professional ethics for the army's health service primarily consists of keeping a dialogue and developing teaching towards command, that simultaneously pertains to ethical thought (Decree n॰81-60 of the Military Medical Practices for Military Physicians, and Pharmacists). In particular this concerns questions of usage of doping molecules or of development by the arms industry and the command of arms systems touching the psychophysiological integrity of the combatant. The Military's health service created an ethics committee in 1987 (Instruction n²45/DEF/DCSSA/EPG/ECX of 26 May 1987 Concerning Composition and Functioning of Deontological Health Military Council). One of the elements of reflection of this committee concerned what we call a pharmacological accompaniment of military in operation or in a critical situation, to maintain vigilance and to raise the "fatigue threshold”. Numerous questions arise regarding the legitimacy of use of these operational aids: is it to respect an operational tempo? Is it to increase performance? Is it to give more security in a critical situation? Is it to make the most of a system or is it to warn about death, alleviation of a physical or mental faculty? To go further into the reasoning it is legitimate to ask the question of how if we obey an interest that is operational and strategic by taking advantage of cognitive functions or if we decide on valorising the preservation of the group or be dependent on the combatant?

The clearest answer recognised by the health service is the prescription which returns with any medicinal substance taken outside of medical use in a pathological context. This concerns obligatory preventative vaccinations, preventative medications with potential use in chemical weapons, the use of certain emergency medical products for calming a combatant's pain and psychotropic stimulants (Instruction no. 744/DEF/DCSSA/AST/TEC Relative to the Use of Substances Modifying Vigilance in Operation Since 31 March 2008). If command is responsible for ordering the substances to be taken, the ordered prescription has numerous deontological implications for the doctor. Further more they are a problem for operational research on the effects of some psychotropics used outside of evaluation. On location the doctor is implicated when he is not responsible for the prescription yet he is implicated in the management and the after effects linked to the substances. Doctors can also be accountable for the consequences in the long term, on physical health as much as mental health. This deontological involvement concerns a whole collective responsibility of the military health service, which weighs heavily on those 
who are in charge.

\section{Conclusion}

One of the criteria used by the paleo-anthropologists to distinguish the human gender is the production of tools. Man is certainly not the only creature capable of grabbing hold of an object to improve his efficiency, but he is the only one who can obtain it by work, that is to say by transformation of nature, and transmitting it to its progeny, through education, his production techniques and use. At all times man has searched the means to be more powerful, to go faster and further, to be more energetic and more efficient. Tools extend and increase, sometimes considerably, our cognitive, intellectual, physical, individual and group capabilities. What would we do today, without books, computers or cars? "Tools", methods multiply to educate or manage more efficiently. To invoke a myth "authenticity of human relations", is to consider that the technical preoccupation is human denial, and actually it is the human himself. It is at least one of these facets, because we must not forget that it is in war, the conquest of new territories, weapons production developed, since its origins, this concern for technical efficiency. If the strategical thought founded on the idea that the hoped for end determines the deducted means, is firstly applied to war, it has quickly found an echo in the political arena in the Renaissance by Machiavel, and in the economic arena with the industrial revolution. The exclusive rule of efficiency, its unique or supreme value, can be held accountable for the worst barbarisms, principally in the last century, ours, and in all three of these areas; military, political and economical. Thankfully, the functional criteria and the value of efficiency are far from exhausting a humane world which characterises itself by the existence of moral judgements and institutions governing social life, likewise narratives (myths) and art works which reproduce a sense in the world.

One must remember here that the ethical dimension is not governed by the preoccupation of efficiency but by the preoccupation of happiness (and in this dimension that we call moral, by the ability to mean well, we can see a component of a search for happiness). In practice in institutions, notably military, the ethical question is directed at the leaders on two distinct levels. Firstly, the question to ask is if the pursued end is the right one. Subsequently if the reply is positive, the question to ask is if the means undertaken were the best. Every time a decision is made it necessitates carrying out a judgement and to judge one needs to lean on a system of values (and to share this if it is a collective decision).

Ethics are always problematic: it starts with a question, of which the importance is not necessarily the reply (always temporary), but its backlash and deepening. Bioethics were born from an interrogation on medical research and practice when medical ethical answers were not sufficient, notably problems faced by new possibilities enabled by genetics. Today it cannot avoid thoughts on the direction of research to improve cognitive capabilities and the application which follows from the results in the context of military operations. "Science's role is not to decide (that is the politician's), but to lift the limits, dangers and risks inherent in new technology" (Queyroy, 2007). It is also to monitor its real use, to see the message which could be being carried out in practice, and to alert the authorities in the event of the emergence of a new detected danger (something which is already done with pharmacovigilance and matériovigiliance). It is quite clear that science presents problems that ignorance would not know how to solve. In effect it is infinitely simpler to conceive a new technological application than to ensure integration in the middle of one who must receive it. Debates today on the medically assisted procreation clearly show that technology supporting this application was perfectly finalized well before the companies in which they could be used had identified the stakes that they raised, as their values, often declared unchangeable and found themselves literally shocked. How then do we ensure that spaces, real or virtual exist so thought can unfurl in its own time and have pauses so that technological developments seem badly adapted to these necessary deferments?

This symposium invites you to take a pause. It invites reflection on a new calibration of synergies between scientific developments and societies which authorise and welcome them. The presentations delivered must react a little like a prism which decompartmentalizes the authors disciplines and which provides stacks of light susceptible to a better understanding of how the stakes can be recombined to be better situated in current possibilities, and from this, questioning the augmentation of cognitive capabilities in general, and in particularly in an operational situation (Bostrom, 2005; Bostrom \& Sandberg, 2007).

\section{Acknowledgements}

We would particularly like to thank Alain Queyroy, without whom this reflection could not have been brought 
to fruition.

\section{References}

Applications of French Bioethical Law (2008). http://www.senat.fr/rap/r08-107-1/r08-107-11.pdf

Booth, M. (2005). A History of Cannabis. In Picador New-York.

Bostrom, N. (2005). In Defense in Posthuman Dignity. Bioethics, 19, 202-204. http://dx.doi.org/10.1111/j.1467-8519.2005.00437.x

Bostrom, N., \& Sandberg, A. (2007). Cognitive Enhancement: Methods, Ethics, Regulatory Challenges. Sciences and Engeniering Ethics, 15, 311-341.

Briole, G. (1996). Ethics in Military Medicine (Ethique en Medicine Militaire). Médecine et Armées, 24, 649-657.

Cloninger, C. R. (2000). Biology of Personality Dimensions. Current Opinion in Psychiatry, 13, 611-616.

Craig, I., \& Plomin, R. (2006). Quantitative Trait Loci for IQ and Other Complex Traits: Single-Nucleotide Polymorphism Genotyping Using Pooled DNA and Microarrays. Genes, Brain and Behavior, 5, 32-37. http://dx.doi.org/10.1111/j.1601-183X.2006.00192.x

de Quervain, D. J. F., \& Papassotiropoulos, A. (2006). Identification of a Genetic Cluster Influencing Memory Performance and Hippocampal Activity in Humans. Proceedings of the National Academy of Sciences of United States of America, 103, 427-4274. http://dx.doi.org/10.1073/pnas.0510212103

Decree n79-506 of the Military Medical Practices. French Official Journal of 30 June 1979: 1568-1572.

Decree n ${ }^{\circ} 81-60$ of the Military Medical Practices for Military Physicians, and Pharmacists. French Official Journal of 28 January 1981: 354-356.

Engelbart, D. C. (1962). Augmenting Human Intellect: A Conceptual Framework. Summary Report AFOSR - 3223 under Contract AF 49(638)-1024, SRI Project 3578 for Air Force Office of Scientific Research. Menlo Park, Ca., Stanford Research Institute.

Estates General of Bioethics (2009) http://www.ccne-ethique.fr/docs/avis_105_CCNE.pdf

Favre, J. D., Vallet, D., Renaudeau, C., Maitrot, R. C., Debord, T., Clervoy, P., Fidelle, G., Boisseaux, H., de Montleau, F., Southwell, G., \& Arméro, C. (2004). Professional Ethics for Military Medical Practices. Technical Report.

French Public Health Code: Bioethical Law 2004-800 of 6 August 2004. Genesis.

French Public Health Code: Bioethical Law no. 1994-94 of 29 July 1994.

Helland, I. B., Smith, L. et al. (2003) Maternal Supplementation with Very Long Chain Fatty Acids during Pregnancy and Lactation Augments Children's IQ at 4 Years of Age. Pediatrics, 111, 39-44. http://dx.doi.org/10.1542/peds.111.1.e39

Instruction n 245/DEF/DCSSA/EPG/ECX of 26 May 1987 Concerning Composition and Functioning of Deontological Health Military Council, 2425-2426.

Instruction no. 744/DEF/DCSSA/AST/TEC Relative to the Use of Substances Modifying Vigilance in Operation Since 31 March 2008.

Jonas, H. (1990). Ethics for Future (Ethique pour le Futur). In Rivages Paris France.

Jones, J. H. (1993). Bad Blood: The Tuskegee Syphilis Experiment. New York: The Free Press.

Kant, E. (1788). Critique of Practical Reason.

Kass, L. (2002). Foreword. In Human Cloning and Human Dignity: An Ethical Inquiry, Report of the President's Council on Bioethics. New York: Public Affairs.

Kolnai, A. (1976). Dignity. Philosophy, 51, 251-271. http://dx.doi.org/10.1017/S003181910001932X

Macklin, R. (1992). Universality of the Nuremberg Code. In: G. J. Annas, \& M. A. Grodin, Eds., The Nazi Doctors and the Nuremberg Code: Human Rights in Human Experimentation (pp. 240-257). New York: Oxford University Press.

Mann, S. (2001). Wearable Computing: Toward Humanistic Intelligence. IEEE Intelligent Systems, 16, 10-15. http://dx.doi.org/10.1109/5254.940020

Mann, S., \& Niedzviecki, H. (2001). Cyborg: Digital Destiny and Human Possibility in the Age of the Wearable Computer. Toronto, Doubleday Canada.

Naboun-Grappe, V. (2000). Alcohol and War in Ex-Yugoslavia 1991-1993 (Alcool et Guerre en ex-Yougoslavie 1991-1993). Autrement Paris France, 191, 155-171.

Nanoquebec.ca (2005) http://www.nanoquebec.ca_w/site/explorateur.jsp?/currentlySelectedSection+259/

Queyroy, A. (2007). How Improving Performances: Well-Being or Doping? Neurosciences Cycle, Brain and Mental Health: 
A Political Cause? www.vivagora.org

Roubertoux, P. (2004). Do Comportemental Genes Exist? (Existe-t-il des gènes du comportement?) Paris: O Jacob.

Surowiecki, J. (2004). The Wisdom of Crowds: Why the Many Are Smarter Than the Few and How Collective Wisdom Shapes Business, Economies, Societies and Nations, Doubleday.

Warwick, K., Gasson, M. et al. (2003). The Application of Implant Technology for Cybernetic Systems. Journal of the American Medical Association Neurology, 60, 1369-1373. http://dx.doi.org/10.1001/archneur.60.10.1369 